Revista Tecné, Episteme y Didaxis: TED. Año 2014, Número Extraordinario. ISSN Impreso: 0121-3814, ISSN web: 2323-0126 Memorias, Sexto Congreso Internacional sobre Formación de Profesores de Ciencias. 08 al 10 de octubre de 2014, Bogotá

\title{
Miradas De La Biodiversidad Y La Diversidad Cultural: Una Reflexión A Propósito De La Enseñanza De Las Ciencias
}

\author{
María Rocío Pérez Mesa'
}

Categoría 2. Trabajos de investigación

\section{Resumen}

Esta comunicación es una reflexión de algunos de los avances de la Tesis Doctoral: Concepciones de Biodiversidad desde la perspectiva de la Diversidad Cultural. Estudio comparado con Docentes en formación inicial de la Licenciatura en Biología, de la línea Enseñanza de las ciencias, contexto y Diversidad cultural, DIE-UD, a través de una revisión documental que aborda como ejes: ámbito conceptual, aportes de los trabajos y categorías emergentes. Como conclusiones se muestra que las diferentes perspectivas acerca de la Diversidad Biocultural a pesar de la relevancia que plantea para la permanencia de la vida en todas sus manifestaciones, formas y procesos dentro de los debates contemporáneos, aún resulta incipiente su abordaje en la enseñanza de las ciencias.

\section{Palabras Claves}

Biodiversidad, Diversidad Biocultural, Enseñanza de las ciencias

\section{Introducción}

La llamada crisis de la biodiversidad, junto con la crisis ambiental, que se denuncia a mediados y finales del siglo XX, no se debe desligar de la llamada crisis de civilización y en ultimas de la crisis del conocimiento (Leff, 2006). Esta crisis plantea fuertes cuestionamientos al proyecto de la modernidad y la ruptura epistémica y ontológica que crea una serie de dualismos hombremujer, cultura-naturaleza, al hacer de la razón instrumental la única vía para conocer, apropiar y dominar la naturaleza (Santos, 2009; Shiva, 1995) bajo un intenso y sostenido proceso de explotación, que legitima un solo conocimiento universal, en cuya historicidad se incluye la traducción de los saberes locales indígenas a la botánica ilustrada de España, en el marco de la Historia natural (Nieto, 2006), y la devastación que se ha agudizado desde la revolución industrial y hasta nuestros días.

\footnotetext{
1 Docente de Planta. Universidad Pedagógica Nacional.mrociop@gmail.com
} 
Revista Tecné, Episteme y Didaxis: TED. Año 2014, Número Extraordinario. ISSN Impreso: 0121-3814, ISSN web: 2323-0126 Memorias, Sexto Congreso Internacional sobre Formación de Profesores de Ciencias. 08 al 10 de octubre de 2014, Bogotá

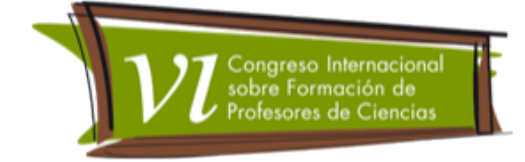

Las problemáticas actuales muestran la necesaria reconsideración de estas formas de conocer y de intervenir el mundo, donde se han propiciado toda suerte de desigualdades y marginalización de las culturas. En tal sentido, se empieza a reconocer por diferentes investigadores que las zonas donde se alberga la mayor biodiversidad del planeta corresponden a regiones con alta presencia de diversas culturas étnicas y campesinas (Maffi, 2002; Posey, 1999; Toledo, 2008) en los países llamados subdesarrollados.

De otra parte, la educación y en especial la educación en ciencias en su constitución y desarrollo ha privilegiado una forma de conocimiento, que deja por fuera los saberes locales al catalogarlos en algunos casos de erróneos y opuestos a la formación de los ciudadanos. Esta situación se traduce en una forma de mantener las asimetrías del conocimiento e invisibilizar las culturas, al ejercer un dominio de una cultura sobre otra (Freire, 1972) que desconoce las creencias, los valores y conocimientos, además de servir de mecanismo para reproducir este proyecto cultural moderno. Sin embargo este enfoque ha empezado a ser objeto de discusión por parte de investigadores en el campo de los estudios culturales de la ciencia y su enseñanza, así como perspectivas más plurales que plantean la posibilidad de establecer puentes entre conocimientos en el contexto escolar (Molina, Mojica, 2013) como una invitación para alterar el mapa político de la educación en ciencias.

\section{Ámbito conceptual}

Para abordar la biodiversidad y la diversidad biocultural, es importante considerar los orígenes y definiciones de los términos que nos permiten contemplar las diferentes consideraciones no sin antes señalar la polisemia que subyace en la expresión Biodiversidad. Así de acuerdo con Pérez,( 2013), el origen del termino biodiversidad surge durante el coloquio de promoción del Foro Nacional de Biodiversidad en la Universidad de Texas, llevado a cabo en 1986, por parte del profesor, Edward O. Wilson, al definirla como: "Toda variación de la base hereditaria en todos los niveles de organización, desde los genes en una población local o especie, hasta las especies que componen toda o una parte de una comunidad local, y finalmente en las mismas comunidades que componen la parte viviente de los múltiples ecosistemas del mundo" Wilson, 1997.

Así mismo, Posey (1999), acuña el termino de Diversidad Biocultural para referirse a un "vínculo indisoluble" entre la diversidad biológica y cultural, con el ánimo de llamar la atención a la relación entre la biodiversidad y la diversidad humana en gran parte porque muchas de las zonas del planeta de mayor diversidad biológica están habitadas por los pueblos indígenas y tradicionales, 
Revista Tecné, Episteme y Didaxis: TED. Año 2014, Número Extraordinario. ISSN Impreso: 0121-3814, ISSN web: 2323-0126 Memorias, Sexto Congreso Internacional sobre Formación de Profesores de Ciencias. 08 al 10 de octubre de 2014, Bogotá

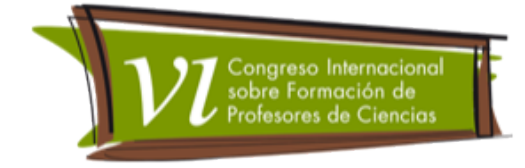

argumentos que se deben respaldar a través de su divulgación en la Declaración de Belém (1999). Sin embargo esto implica empezar a hacer una revisión crítica de lo que representa, en cuanto a pluralidad de formas de concebir el mundo, de establecer relaciones con la biodiversidad y de establecer estrategias para su conservación, sin que sean eclipsadas por las propuestas que desde occidente se establecen en el marco de la conservación de la biodiversidad, así como su problematización en el campo de la enseñanza de las ciencias.

\section{¿Qué nos dicen los trabajos analizados sobre la diversidad biocultural y la Articulación con la educación y la enseñanza de las ciencias?}

La revisión documental permite apreciar el posicionamiento que ha tenido el debate acerca de las formas de conocer por parte de las culturas locales y su relevancia en el cuidado y producción de la biodiversidad en una conexión entre la naturaleza y los seres humanos, que expresan las complejas y diversas nociones de la biodiversidad articuladas a las tradiciones culturales. Dentro de los diversos trabajos que abordan esta relación entre la diversidad cultural y la diversidad biológica, emergen como ejes a) Biodiversidad y perspectiva de género; b) Biodiversidad y Contexto cultural; c) Biodiversidad y conocimientos locales; y d) Diversidad biocultural y enseñanza de las ciencias.

\section{a) Biodiversidad y Perspectiva de Género}

Esta categoría empieza a ser objeto de discusión y debate en cuanto, a que se plantea de una parte la redefinición del termino biodiversidad, al considerar que éste solo se ocupa de los seres vivos y deja por fuera la vida que está presente en el agua, las rocas, el aire y demás seres de la naturaleza, por lo que se estima que todo sería biodiversidad, y esto tendría connotaciones en términos de la protección del territorio y de la cultura, así como una postura epistémica y ontológica que debe ser considerada a nivel internacional y local. Así mismo, los conocimientos y practicas ancestrales muestran la continuidad entre naturaleza y cultura, inherentes a la cosmovisión y experiencias como mujeres indígenas que han aportado al conocimiento, manejo y producción de la biodiversidad, aunque con una preocupación creciente como es la erosión de los conocimientos ancestrales por las formas de intervención a nivel científico, técnico y educativo por parte de occidente que provoca asimetrías, desigualdades y pone en riesgo la permanencia de las culturas y de la biodiversidad. Ramírez, (2005); Silva (2005); Pérez (2007); Arrieta (2007). 
Revista Tecné, Episteme y Didaxis: TED. Año 2014, Número Extraordinario. ISSN Impreso: 0121-3814, ISSN web: 2323-0126 Memorias, Sexto Congreso Internacional sobre Formación de Profesores de Ciencias. 08 al 10 de octubre de 2014, Bogotá

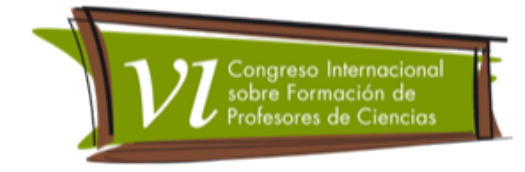

b) Biodiversidad y Contexto cultural

Se plantea una estrecha relación entre las zonas de distribución de la biodiversidad y los contextos culturales con especificidades y condiciones particulares de las comunidades étnicas y campesinas, que hacen de estos lugares unas zonas de transición donde dos o más culturas convergen e interactúan, con una potencialidad en términos del mantenimiento y uso de la biodiversidad y de los intercambios culturales entre los diversos grupos y diversidades lingüísticas. En tal sentido, los pueblos indígenas que se encuentran en áreas con una alta incidencia de bordes ecológicos, les permite crear activamente y mantener la biodiversidad. Estas prácticas les proporcionan una mayor diversidad de capital cultural y ayuda a mantener su flexibilidad y capacidad de recuperación. Turner, Davidson, ,O'Flaherty, (2003).

\section{c) Biodiversidad y conocimientos locales}

Las relaciones entre grupos indígenas y campesinos con la biodiversidad, plantea la complejidad de visiones sobre los conocimientos locales, que se expresan en una amplio conocimiento de las plantas, su recuperación y producción acompañada de un conocimiento especializado a nivel de la medicina tradicional que permite de una parte proteger la biodiversidad, plantear unas formas de clasificación de la naturaleza y desarrollar practicas milenarias acerca del cuidado de la vida humana, una relación simbiótica entre los hábitats y culturas (Phondani; Maikhuri; Bisht, 2013) en una idea de armonización de las relaciones. Megaloudi, F. (2005); Ayantunde; Briejer; Hiernaux; Udo y Tabo (2008). Así mismo se muestra un conocimiento sofisticado de las especies de plantas, sin diferencias significativas entre hombres $y$ mujeres, en las categorías de uso general, tales como plantas medicinales, plantas para la construcción y bienes nacionales. Camou-Guerrero; Reyes; Martínez; y Casas (2008).

\section{d) Diversidad biocultural, educación y enseñanza de las ciencias}

En investigaciones sobre la etnia mapuche se evidencian procesos de marginalización y discriminación dado que históricamente, la escolarización de niños/as mapuches se ha realizado con base en contenidos educativos monoculturales occidentales como es el caso de la enseñanza de las ciencias, sin explicitar ambas lógicas de conocimientos, occidental y mapuche en la educación escolar, generando un conflicto socio cognitivo que afecta la construcción de la identidad individual y sociocultural de niños y jóvenes. (Quintrique, et al., 2009; Contreras, 2009). De igual forma, esta situación se evidencia en los resultados de O’Hern (2010) con estudiantes y profesores de Kenya, quien muestra la influencia occidental de las ciencias en el currículo 
Revista Tecné, Episteme y Didaxis: TED. Año 2014, Número Extraordinario. ISSN Impreso: 0121-3814, ISSN web: 2323-0126 Memorias, Sexto Congreso Internacional sobre Formación de Profesores de Ciencias. 08 al 10 de octubre de 2014, Bogotá

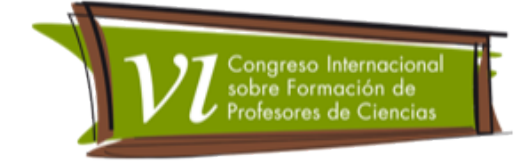

formal de la escuela, señalando que no les es posible deconstruir el paradigma colonial y hegemónico, a través del cual dicho conocimiento ha sido concebido, organizado, administrado y evaluado, dejando por fuera su conocimiento de la diversidad local (Pérez, 2013).

Dopico \& García (2011), proponen la enseñanza del ambiente a través de la inmersión en la vida cultural de las zonas rurales, de manera que los estudiantes participen a través de la investigación con las prácticas culturales tradicionales. Así mismo, Baptista \& El-Hani (2009), en su propuesta de enseñanza, elaboran material didáctico que involucra el conocimiento tradicional y el conocimiento científico, favoreciendo el aprendizaje en los estudiantes procedentes de comunidades tradicionales para ser más exitosos, al involucrar sus conocimientos sobre plantas en el aula. (Pérez, 2013).

\section{Conclusiones}

Los proyectos, investigaciones y discusiones que fueron analizados plantean retos a la enseñanza de las ciencias y la formación de profesores, al hacer de la diversidad biocultural un asunto relevante para ser considerado desde una perspectiva más plural de las epistemologías y conocimientos de las diversas culturas y su trascendencia en las formas de relacionarse, proteger y aportar en la producción de la biodiversidad, a propósito de la llamada crisis de la biodiversidad y la crisis del conocimiento, que implica hacer visibles las asimetrías, las desigualdades bajo la hegemonía instaurada desde el proyecto fundacional de la modernidad y la colonialidad del saber/poder, para empezar a democratizar la enseñanza, posibilitar la construcción de puentes entre conocimientos y aportar desde una perspectiva más integradora al cuidado de la vida, la equidad y la justicia social que se corresponda con las realidades de un país biodiverso, pluriétnico y multicultural.

\section{Referentes bibliográficos}

Arrieta, N. (2007). Conocimiento tradicional y biodiversidad zenú, San Andrés de Sotavento, Colombia. En Donato, Escobar, Escobar, Pazmiño y Ulloa (eds.), Mujeres indígenas, territorialidad y biodiversidad en el contexto latinoamericano. Bogotá: Universidad Nacional de Colombia.

Baptista, G. y El-Hani, C. (2009). The Contribution of Ethnobiology to the Construction of a Dialogue Between Ways of Knowing: A Case Study in a Brazilian Public High School. Science \& Education, 18:503-520. 
Revista Tecné, Episteme y Didaxis: TED. Año 2014, Número Extraordinario. ISSN Impreso: 0121-3814, ISSN web: 2323-0126

Memorias, Sexto Congreso Internacional sobre Formación de Profesores de Ciencias. 08 al 10 de octubre de 2014, Bogotá

Profesores de Ciencias. 08 al 10 de octubre de 2014, Bogotá

Dopico, E., Y García, E. (2011). Leaving the Classroom: A Didactic Frameworkfor Education in Environmental Sciences. Cultural Studies of Science Education, 6 (2), pág. 311-326.

Freire, P. (1972).Pedagogía del oprimido. Buenos Aires: Siglo XXI Argentina Editores.

Nieto, M. (2006). Remedios para el Imperio: historia natural y la apropiación del nuevo mundo. Bogotá, Colombia: Universidad de los Andes.

Molina, A y Mojica, L. (2013) Enseñanza como puente entre conocimientos científicos escolares y conocimientos ecológicos tradicionales. Magis ,6(12), pág. 37-53.

O'Hern, D. (2010). Indigenous and Western Knowledges in Science Education: An Ethnographic Study of Rural and Urban Secondary Schools and Classroomsin Kenya. (Tesis doctoral inédita). University of Buffalo, Estados Unidos.

Pérez, M. R. (2013). Concepciones de biodiversidad: una mirada desde la diversidad cultural. Magis, 6 (12), pág. 133-151.

Quintriqueo, S., y McGinity, M. (2009). Implicancias de un modelo curricular monocultural en la construcción de la identidad sociocultural de alumnos/as mapuches. Chile. Revista Estudios Pedagógicos, 35 (2), pág. 173-188. 